\title{
Vertical distribution and sources of PAHs in different agricultural soil profiles: a case study in Jianghan Plain, Central China
}

\section{Zeya Wang}

Wuhan University of Science and Technology

\section{Xiangyi Gong ( $\nabla 2546407485 @ q q . c o m$ )}

Wuhan University of Science and Technology https://orcid.org/0000-0001-9151-4805

Jiaquan Zhang

Hubei Polytechnic University

\section{Dajun Ren}

Wuhan University of Science and Technology

\section{Dekang Meng}

Wuhan University of Science and Technology

\section{Research Article}

Keywords: PAHs, soil, DOM, crops

Posted Date: June 2nd, 2021

DOI: https://doi.org/10.21203/rs.3.rs-576893/v1

License: (9) This work is licensed under a Creative Commons Attribution 4.0 International License. Read Full License 


\section{Abstract}

PAHs are one of the persistent organic pollutants (POPs) and widely distributed in nature. This study aimed to investigate the distribution and origination of polycyclic aromatic hydrocarbons (PAHs) in 3 different agricultural soil profiles (paddy, cotton and rape). The study found that 16 PAHs were all detected in 3 soil profiles, where the concentrations of $\sum_{16} \mathrm{PAHs}$ ranged from $122.37-664.13 \mathrm{ng} / \mathrm{g}$ in surface soil and $24.15-109.76 \mathrm{ng} / \mathrm{g}$ in bottom soil. Compared to other areas, the concentrations were higher than most plains, but lower than several cities. The $\sum_{16} \mathrm{PAHs}$ of naphthalene(Nap) counted the most in nearly every sample. The total concentrations of $\sum_{16} \mathrm{PAHs}$ were higher in shallow soil and decreased sharply with the increase of depth, while those were smoothly distributed in paddy field (PF). The results showed that 3 soil profiles were all weakly alkaline $(8<\mathrm{pH}<9)$, and PAH concentrations in soil were linearly related with total organic carbon (TOC) at different depths except for the PF soil profiles. It was the flooded tillage method in PF that caused the different characteristics of distribution and physicochemical properties. There were high correlation between dissolved organic matters(DOM) and PAH concentrations in cotton field (CF). However, there were no correlations between concentrations of PAHs and other 3 properties ( $\mathrm{pH}$, clay miners). By the ratio method, PAHs were revealed mainly derived from combustion, and then petroleum.

\section{Introduction}

PAHs are ubiquitous persistent organic pollutants (POPs), occurring as 2 or more fused benzene rings and appearing colorless, white/pale yellow with high melting, boiling point, low vapor pressure(Waigi et al. 2015). They are derived from both natural and anthropogenic emission sources such as combustion, petroleum, chemical industry, etc. PAHs can be transported far away from their sources and difficult to degrade into harmless substances. They are carcinogenicity, teratogenicity and mutagenicity. For example, The simplest and volatile member of the PAHs, Naphthalene (Nap), commonly used in industrial materials and moth-proofing, has been considered carcinogenic through a lot of experiments on animals(Liu et al. 2020); benzo[a]pyrene (BaP) are not only carcinogenic but also mutagenic endocrine disruptors (Shimada et al. 2020). Therefore, 16 PAHs have been identified as priority pollutants by United States Environmental Protection Agency (USEPA) and the Europian Union (EU) due to their toxicity and associated risks to human health and the environment.

Soil is the major reservoir of PAHs due to the strong sorption and water holding capacity (Sun et al. 2019). The vertical distribution of PAHs in soil are affected by many processes, including diffusion of air and water, advection of percolating water, vertical migration of macropores and chemical degradation. Cavalcanti et al. (2021) pointed out that the oil hydrocarbon (including PAHs, alkanes and other matters) leakage led to soil pollution of PAHs and blockage of soil pores. Chemical plants are also one of PAHs contributors. Twelve soil samples contaminated with PAHs were collected from five former gasworks by Beriro et al. (2020) in England and Wales, UK. The $\sum_{16}$ PAHs were detected in the soils ranged from 51 to 1440 mg/ kg. Li et al. (2010) detected soil PAHs from an old oven plant in Beijing, China. Total PAH 
concentrations there ranged from 6.27 to $40.18 \mathrm{mg} \cdot \mathrm{kg}^{-1}$ dry weight. In addition, they found the highest concentration occurred in the $250-500 \mu \mathrm{m}$ size fraction.

Under the prevalence of straw burning and sewage irrigation condition in China, cultivated soil also became a serious area for PAHs accumulation (Chen et al. 2018; Khan et al. 2008). PAHs were transferred from soil to crops and brought potential health risk (Chai et al. 2017). Chen et al. (2018) investigated the accumulation characteristics in the home garden and agricultural field. They found that the average PAHs concentrations there reached to $508.9 \mathrm{ng} / \mathrm{g}$ and $589.9 \mathrm{ng} / \mathrm{g}$, respectively. The farmland in Yangtze River Delta region was also reported polluted by PAHs (Wang et al. 2017). The average concentrations of 16 PAHs in surface soil and subsoil were $471.30 \mathrm{mg} / \mathrm{kg}$ and $341.40 \mathrm{mg} / \mathrm{kg}$, respectively. The kinds of crops may affect the concentrations of pollutants in soil. For example, Mentha viridis is easier to absorb cadmium, while Solanum tuberosum is easier to transfer both cadmium and zinc from soil (Jan et al. 2010). And the cucurbitaceae family, including cucumbers, squashes and zucchinis, can accumulate high concentrations of hydrophobic pollutants from soils (Fujita et al. 2020). In addition, tillage of flooded soil may influence the distribution of pollutants by changing the physical and chemical properties of soil. It was reported that microbial communities in flooded paddies differ from those in rainfed croplands(Wang et al. 2020), and they had different degradation of organic pollutants. However, there are few reports about the vertical distribution of PAHs in different crop soils.

In our work, soil samples were collected from a farmland nearby Qianjiang city, in Jianghan Plain, China, where is one of the most important grain-production areas and agriculture base in China(Wang et al. 2020). In recent years, several studies indicated that organic pollutants, such as antibiotics and phthalate acid esters, were detected in the study area (Liu et al. 2010; Tong et al. 2017). The objectives of this study are: (1) to investigate the concentrations and vertical distribution of PAHs in 3 cultivated soil; (2) to reveal the anthropogenetic activities and soil properties influencing the vertical distribution in 3 soil profiles and (3) to identify the sources of PAHs.

\section{Material And Methods}

\subsection{Sample collection}

Sampling points are located by portable GPS satellite (Fig. 1). Soil profiles (C1-C3) were simultaneously collected from the paddy field (PF), the cotton field (CF) and the rape field (RF) in 2017, which are all representative crops here. We measured the depth of the soil profiles with a ruler and took a sample every $20 \mathrm{~cm}$ until $120 \mathrm{~cm}$. In particular, we also collected the surface soil samples at $10 \mathrm{~cm}$ and the deepest soils at $120-150 \mathrm{~cm}$. Then the samples we took were all wrapped with aluminum foil, stored in sealed polythene bags, and freeze dried at $-20^{\circ} \mathrm{C}$ before extraction.

\subsection{Sample treatment and PAH analysis}


The procedure of preparation of PAH analysis referred to Hu et al. (2017). briefly, we took and injected $10 \mathrm{~g}$ soil samples with PAH surrogates (naphthalene-d8, acenaphthene-d10, phenanthrene-d10, chrysened12 and perylene-d12), and Soxhlet-extracted it with dichloromethane (DCM) for 48h. The extracts were concentrated and solvent-exchanged with $1 \mathrm{ml}$-hexane to $2-3 \mathrm{ml}$ by a rotary evaporator (Heidolph 4000 , Germany) and then cleaned up by deactivated alumina/silica gel column $(1: 2, \mathrm{v} / \mathrm{v})$. We then used $30 \mathrm{~mL} \mathrm{DCM}$ /hexane (2:3) to elute PAHs. The eluent was finally reduced to $0.2 \mathrm{ml}$ under a pure nitrogen stream. Before the instrumental quantitation of PAHs, every sample was added with a known quality of hexamethylbenzene as an internal standard.

In this study, we mainly analyze 16 priority PAH compounds proposed by the U.S. Environmental Protection Agency(EPA): naphthalene (Nap), acenaphthylene (Acy), acenaphthene (Ace), fluorine (Flu), phenanthrene (Phe), anthracene (Ant), fluoranthene (Fla), pyrene (Pyr), benzo(a)anthracene (BaA), chrysene (Chr), benzo(b)fluorantene (BbF), benzo(k)fluoranthene (BkF), benzo(a)pyrene (BaP), indeno(1, 2, 3-cd)pyrene (IcdP), dibenzo(a, h)anthracene (DBA) and benzo( $g, h, i)$ perylene (BghiP).

PAHs were analyzed by GC-MS (Agilent $6890 \mathrm{~N} / 5975$ MSD) equipped with a DB- 5 capillary column (30m $\times 0.25 \mathrm{~mm}$ i.d $\times 0.25 \mu \mathrm{m}$ film thickness). Helium (99.999\%) was used as the GC carrier gas, with a constant flow rate of $1.5 \mathrm{ml} \mathrm{min}{ }^{-1}$. Every $1 \mu \mathrm{L}$ extracted sample was injected with splitless mode. The chromatographic conditions were set as follows: the injector temperature was set at $270^{\circ} \mathrm{C}$; the detector temperature was set at $280^{\circ} \mathrm{C}$; the oven temperature was initially set at $60^{\circ} \mathrm{C}$ for 5 minutes, then increased to $290^{\circ} \mathrm{C}$ at a rate of $3^{\circ} \mathrm{C} \mathrm{min}-1$, and ultimately maintained at $290^{\circ} \mathrm{C}$ for 40 minutes.

\subsection{Quality assurance/quality control}

In this analysis program, the quality control procedures included method blanks, spiked blanks and sample duplicates. There was no interference in the blanks. The instruments were calibrated every day against reference materials. The surrogate standards, which were mentioned above, were added to all the samples to check the procedural functions and matrix effects. In the samples, the mean recoveries were $77.0 \pm 9.5 \%$ to $109 \pm 8.8 \%$.

\section{Result And Discussion}

\subsection{Concentrations of PAHs in soil}




\begin{tabular}{|c|c|c|c|c|}
\hline \multirow[t]{2}{*}{ Locations } & \multirow[t]{2}{*}{$\mathrm{n}$} & \multicolumn{2}{|c|}{$\sum \operatorname{PAHs}\left(\mathrm{ng} \cdot \mathrm{L}^{-1}, \mathrm{ng} \cdot \mathrm{g}^{-1}\right)$} & \multirow[t]{2}{*}{ Reference } \\
\hline & & Mean & Range & \\
\hline Three Gorges Reservoir, China & 16 & 133.84 & $54.00-463.08$ & (Hu et al. 2017) \\
\hline West Plain, Florida, the USA & 16 & 4055 & $950-11451$ & (Gao et al. 2019) \\
\hline Yangtze River Delta, China & 16 & 266.6 & $10.1-3058.6$ & (Cai et al. 2017) \\
\hline Huanghuai plain, China & 16 & 129.5 & $15.7-1247.6$ & (Yang et al. 2012) \\
\hline Western Tibetan plateau, China & 16 & 30.8 & $14.4-59.5$ & (Zhou et al. 2018) \\
\hline Farmlands of Henan Province, China & 15 & 24.2 & $6.91-72.4$ & (Feng et al. 2017) \\
\hline Rawalpindi, Pakistan & 16 & 763 & $201-1634$ & (Saba et al. 2012) \\
\hline Terai Belt, North India & 16 & 20.95 & $10.24-43.85$ & (Masih et al. 2014) \\
\hline Suburb of Taihu plain, China & 16 & 4420 & $4-32449$ & (Cui et al. 2008) \\
\hline Jianghan Plain, China & 16 & 393.12 & $122.37-664.13$ & This study \\
\hline
\end{tabular}

In PF and CF, The 2-ring PAHs were the most and the 6-ring PAHs counted the least in every samples, while the 3-ring PAHs counted more in RF. Nevertheless, the low-molecule-weight (LWM) PAHs (2, 3-ring PAHs) counted more in every samples in PF. Figure 3 showed each PAH concentrations among 16 PAHs in 3 soil profiles. The PAHs of Nap and Phe was generously detected in every sample. On the range of the depth of 0-40cm, HWM PAHs, especially the 7-16th PAHs(Fla, Pyr, B(a)A, Chr, B(b)F, B(k)F, B(a)P, Ind, Dib and $\mathrm{B}(\mathrm{ghi}) \mathrm{P}$ ) were less detected in $\mathrm{PF}$, but more detected in the deeper depth of $60-150 \mathrm{~cm}$.

Among the 3 profiles, in general, the surface soil of CF presented the highest concentration of PAHs, while that of PF presented the lowest concentration. We can find that the concentrations of PAHs in the samples of CF and RF have the similar trend as the depths changed. In CF and RF, the concentrations of PAHs, especially of high-molecule-weight (HWM) PAHs (4, 5, 6-ring PAHs), dropped sharply as the depths increased in shallow soil (soil depth $<50 \mathrm{~cm}$ ) and then tended to be stable. By comparison of CF and PF, the PAH concentrations in PF were evenly distributed in the profile. In profiles of CF and RF, HMW PAHs were dominant above $30 \mathrm{~cm}$, but LMW PAHs took over in the soil below

$50 \mathrm{~cm}$. In the profile of PF, LMW PAHs were the majority (Fig. 4). One of the reasons influencing the vertical distribution characteristics of 3 sampling points was the topography of Jianghan Plain. It is a humid alluvial plain, where groundwater level fluctuated more than $1 \mathrm{~m}$. This movement may intensively affect the vertical distribution of organic contaminants(Liu et al. 2010). The other reason was the characteristics of crops themselves as well as their tillage methods. First, the 3 crops have different 
adsorption and degradation capacity with their distinctive rhizosphere microorganisms for PAHs. For example, potential PAH-degrading genes exist in both soil bacteria and endophytic bacteria, which are associated in soil and rice grain(Lu et al. 2021). Due to the low degradability and high hydrophobicity (Sun et al. 2019), HMW PAHs were mostly detected in surface soil, especially in surface cotton soil (CS) and rape soil (RS). Second, rice is mostly grown under flooded lowland conditions. In a paddy field, from crop establishment to harvest, rice goes through the 3 processes: tillage of flooded soil (puddling), rice transplantation and the crop growth in a submerged environment (Yang et al. 2020). Moreover, the characteristics of rice cultivation are the dry and wet cycle of rice field, i.e. alternate flooding period and intercropping period. Under the condition of submergence during rice cultivation, microbial activity changes from aerobic respiration to anaerobic respiration, therefore, the physical and chemical properties of soil were changed (Kögel-Knabner et al. 2010). In this series of cultivation processes, the PAH concentrations in surface soil would be affected a lot. Therefore, PAH concentrations in surface paddy soil were lower than the other 2 surface soil samples.

\subsection{Influence of the physicochemical properties of soil}

Physicochemical properties of PAHs are reportedly suitable for characterizing their distribution in various environmental media (Cai et al. 2019; Wang et al. 2009). To further reveal the factors affecting the distribution and migration of PAHs in these 3 soil profiles, probable related physical and chemical parameters were detected (Fig. 5). It was in common that the soil was weakly alkaline $(8<\mathrm{pH}<9)$ in these 3 profiles. Through the multiple regression analysis with PAHs and TOC, we can find that there were very significant linear positive correlation in $R F\left(R^{2}=0.961\right)$ and good linear positive correlation in CF $\left(R^{2}=\right.$ 0.712) (Table 3), indicating the vertical distribution of PAHs in RF and CF dramatically influenced by TOC. The similar result was reported by Cai et al. (2019), where in addition put forward that high concentrations of TOC in the surface soil would adsorb PAHs, bringing about a sudden decline of PAHs. However, PAH concentrations in PF exhibited weak correlation with TOC. Similar appearance was reported by Sun et al. (2019). They estimated that PAHs were easy to migrate in catchments. In the PF, the main factor we thought the irrigation water as well as the special farming method influenced the relationships between the concentrations of PAHs and TOC. Soil has the capacity of adsorption to inhibit PAHs migration. Banach-Szott et al. (2015) took TOC and clay minerals both the most critical factors affecting sorption of organic matters. Clays, especially of finer particles, had larger specific surface area and more adsorption sites so that they were better able to adsorb PAHs than the fine or coarse sands (Sun et al. 2019). But little relationship between the concentrations of clay minerals and PAHs was in this study, implying weak influence of clay minerals. In CF, DOM was positively correlated with PAHs concentration $\left(R^{2}=0.827\right)$. DOM could decrease the sorption of PAHs and promote desorption of soil(Yu et al. 2011). However, the study (BjorklundandLi 2017) revealed that DOM could promoted sorption of high hydrophobicity of organic matters. Through further analysis for CF profiles, the percentage of HMWPAHs were positively correlated with DOM, and that of the LMW-PAHs were negatively correlated with DOM(Fig. 6), which showed that DOM decreased the sorption of LMW-PAHs while promoted the sorption of HMW-PAHs. This sorption behavior reduced the vertical migration of HMW-PAHs. 
Table 2

Correlation coefficient between PAHs

concentration and soil physicochemical

indicator

\begin{tabular}{|llll|}
\hline factor & PF & CF & RF \\
\hline TOC & 0.374 & 0.712 & 0.961 \\
\hline Clay minerals & -0.319 & -0.111 & 0.517 \\
\hline DOM & 0.062 & 0.827 & -0.481 \\
\hline pH & -0.402 & -0.020 & -0.511 \\
\hline
\end{tabular}

\begin{tabular}{|lll|}
\hline & Ring & Coefficient \\
\hline LMW PAHs & 2 & -0.819 \\
\cline { 2 - 3 } & 3 & -0.778 \\
HMW PAHs & 4 & 0.843 \\
\cline { 2 - 3 } & 5 & 0.842 \\
& 6 & 0.850 \\
\hline
\end{tabular}

\subsection{Sources of PAHs in soil}

PAHs composition pattern can indirectly reflect the source of environmental pollution. In general, HWM PAHs usually come from the high-temperature combustion process like vehicular exhaust, anthropogenic combustion or pyrogenic sources, and LWM PAHs mainly come from low-or-moderate-temperature combustion process such as coal burning (Yang et al. 2013). For surface soil, the high proportion of HWM PAHs were in the CS and RS (Fig. 4), indicating PAHs chiefly originated from high temperature pyrogenic contamination processes over petrogenic sources. Instead, large scale of LMW PAHs were in the PF, revealing that PAHs there were normally engendered by coal or grass burning.

It is a common method to estimate the source of PAHs from the congener ratios of PAHs. The ratios of several stable PAH isomers have been widely used in order to seek the PAH origination. As is exhibited in Fig. 7, we can directly find that the ratios of Ant/ (Ant + Phe) $>0.1$ and $\mathrm{BaA} /(\mathrm{BaA}+\mathrm{Chr})>0.35$ in PS and $\mathrm{RS}$, indicating PAHs in those 2 samples were mainly derived from combustion. Evidently, straw burning indeed contributed a large number of concentration of soil in surface soil. The ratios that $\mathrm{BaA} / \mathrm{BaA}+$ Chr) $<0.35$ and Ant/ (Ant + Phe) $>0.1$ in CS implied that PAHs were partly originated from oil, but mainly from combustion. The location of CS is close to the road, where plenty of vehicles go through there, causing serious exhaust contamination. More than that, the accidental gasoline leakage can't be neglected due to the near location of the Jianghan Oilfield as well as a large number of oil trucks around. 


\section{Conclusions}

1. PAHs were widespread in the 3 agricultural soil profiles. The levels of PAH concentrations in the study area were higher in comparison with other agricultural plains in China. In general, the concentrations of $\sum_{16} \mathrm{PAH}$ s were higher in the surface soil than in the bottom soil. The LWM PAHs were concentrated in every samples and the HWM PAHs were mostly concentrated in the shallow soil. Furthermore, the 2-4-ring PAHs were dominant under the depths of $40-150 \mathrm{~cm}$. Among 3 profiles, PAHs were the most detected in $\mathrm{CF}$, whereas in the surface or the bottom sample. For CF and RF, the total concentrations of $\sum_{16} \mathrm{PAHs}$ decreased with the profiles deepening.

2. Differently, compared to other 2 profiles, the concentrations of PAHs in PF samples were smoothly distributed in every sample. It was mainly because of the particular farming method, where the soil were flooded in long term. Other reasons influencing the distribution of 3 profiles were the topography and the chemical and physical properties. For properties of soil, the results showed that 3 soil profiles were all weakly alkaline $(8<\mathrm{pH}<9)$. And there were linear positive correlations between TOC and concentrations of PAHs in CF and RF. However, there were no correlations between clay miners and concentrations of PAHs.

3. The ratios of Ant/ (Ant + Phe) $>0.1$ indicated that PAHs in the 3 profiles were mainly originated from combustion. For $\mathrm{CF}$, the ratio of $\mathrm{BaA} /(\mathrm{BaA}+\mathrm{Chr})<0.35$ implied that $\mathrm{PAHs}$ were not only originated from combustion but also petroleum.

\section{Data availability statement}

The data that support the findings of this study are openly available in figshare at https://doi.org/10.6084/m9.figshare.14672289.v1.

\section{Declarations}

\section{Data availability statement}

The data that support the findings of this study are openly available in figshare at https://doi.org/10.6084/m9.figshare.14672289.v1.

\section{Acknowledgements}

This study was supported by Open Research Funds of Hubei Provincial Key Laboratory for efficient utilization of mineral resources and agglomeration, Wuhan University of Science and Technology(2020zy003), and Science and Technology Plan Project(Application Foundation Frontier Project) in Wuhan, China(Grant No.2020020601012274).

\section{References}


1. Banach-Szott,B. Debska,A. Wisniewska\& J. Pakula (2015) Changes in the contents of selected polycyclic aromatic hydrocarbons in soils of various types. Environ Sci Pollut Res Int 22: 5059-5069. 10.1007/s11356-014-3901-9

2. J. Beriro,M. Cave,A. Kim, et al. (2020) Soil-sebum partition coefficients for high molecular weight polycyclic aromatic hydrocarbons (HMW-PAH). J Hazard Mater 398: 122633.

10.1016/j.jhazmat.2020.122633

3. Bjorklund\& L. Li (2017) Removal of organic contaminants in bioretention medium amended with activated carbon from sewage sludge. Environ Sci Pollut Res Int 24: 19167-19180. 10.1007/s11356017-9508-1

4. Cai,J. Li,D. Wu, et al. (2017) Spatial distribution, emission source and health risk of parent PAHs and derivatives in surface soils from the Yangtze River Delta, eastern China. Chemosphere 178: 301-308. 10.1016/j.chemosphere.2017.03.057

5. Cai,Y. Ding,Z. Zhang, et al. (2019) Effects of total organic carbon content and leaching water volume on migration behavior of polycyclic aromatic hydrocarbons in soils by column leaching tests. Environ Pollut 254: 112981. 10.1016/j.envpol.2019.112981

6. Cavalcanti,T. J. M. Fraga,M. A. Loureiro Leite, et al. (2021) In-depth investigation of Sodium percarbonate as oxidant of PAHs from soil contaminated with diesel oil. Environ Pollut 268: 115832. 10.1016/j.envpol.2020.115832

7. Chai,Q. Cheng,J. Wu, et al. (2017) Contamination, source identification, and risk assessment of polycyclic aromatic hydrocarbons in the soils of vegetable greenhouses in Shandong, China. Ecotoxicol Environ Saf 142: 181-188. 10.1016/j.ecoenv.2017.04.014

8. Chen,F. Zhang,J. Zhang, et al. (2018) Accumulation characteristics and potential risk of PAHs in vegetable system grow in home garden under straw burning condition in Jilin, Northeast China. Ecotoxicol Environ Saf 162: 647-654. 10.1016/j.ecoenv.2018.06.082

9. X.-H. Cui,B.-H. Li\& H.-H. Chen (2008) Contamination characteristics and pollutant sources analysis on PAHs in shallow groundwater in suburb of Taihu plain. Huan jing ke xue= Huanjing kexue 29: 18061810.

10. T. Edwards (1983) Polycyclic Aromatic Hydrocarbons (PAH's) in the Terrestrial Environment-A Review1. Journal of Environmental Quality 12: 427-441. 10.2134/jeq1983.00472425001200040001x

11. Feng,X. Li,J. Zhao\& J. Sun (2017) Distribution, transfer, and health risks of polycyclic aromatic hydrocarbons (PAHs) in soil-wheat systems of Henan Province, a typical agriculture province of China. Environmental Science and Pollution Research 24: 18195-18203. 10.1007/s11356-017-9473-8

12. Fujita,Y. Haga,R. Yoshihara, et al. (2020) Suppression of the genes responsible for transporting hydrophobic pollutants leads to the production of safer crops. Sci Total Environ 741: 140439. 10.1016/j.scitotenv.2020.140439

13. Gao,M. Xu,Y. Liu, et al. (2019) Emerging and legacy PAHs in urban soils of four small cities: Concentrations, distribution, and sources. Sci Total Environ 685: 463-470.

10.1016/j.scitotenv.2019.05.403 
14. Hu,J. Zhang,C. Ye, et al. (2017) Status, source and health risk assessment of polycyclic aromatic hydrocarbons (PAHs) in soil from the water-level-fluctuation zone of the Three Gorges Reservoir, China. Journal of Geochemical Exploration 172: 20-28. 10.1016/j.gexplo.2016.09.012

15. A. Jan,M. Ishaq,S. Khan, et al. (2010) A comparative study of human health risks via consumption of food crops grown on wastewater irrigated soil (Peshawar) and relatively clean water irrigated soil (lower Dir). J Hazard Mater 179: 612-621. 10.1016/j.jhazmat.2010.03.047

16. Khan,L. Aijun,S. Zhang, et al. (2008) Accumulation of polycyclic aromatic hydrocarbons and heavy metals in lettuce grown in the soils contaminated with long-term wastewater irrigation. $J$ Hazard Mater 152: 506-515. 10.1016/j.jhazmat.2007.07.014

17. Kögel-Knabner,W. Amelung,Z. Cao, et al. (2010) Biogeochemistry of paddy soils. Geoderma 157: 114. 10.1016/j.geoderma.2010.03.009

18. Li,J. Chen,W. Wu\& X. Piao (2010) Distribution of polycyclic aromatic hydrocarbons in different size fractions of soil from a coke oven plant and its relationship to organic carbon content. $J$ Hazard Mater 176: 729-734. 10.1016/j.jhazmat.2009.11.095

19. Liu,H. Liang,Y. Liang, et al. (2010) Distribution of phthalate esters in alluvial sediment: a case study at JiangHan Plain, Central China. Chemosphere 78: 382-388. 10.1016/j.chemosphere.2009.11.009

20. Liu,J. Bai,H. Yao, et al. (2020) Embryotoxicity assessment and efficient removal of naphthalene from water by irradiated graphene aerogels. Ecotoxicol Environ Saf 189: 110051.

10.1016/j.ecoenv.2019.110051

21. Lu,Y. Hong,E. S. Odinga, et al. (2021) Bacterial community and PAH-degrading genes in paddy soil and rice grain from PAH-contaminated area. Applied Soil Ecology 158. 10.1016/j.apsoil.2020.103789

22. Masih,J. K. Lal\& D. K. Patel (2014) Contamination and Exposure Profiles of Persistent Organic Pollutants (PAHs and OCPs) in Groundwater at a Terai Belt of North India. Water Quality, Exposure and Health 6: 187-198. 10.1007/s12403-014-0126-6

23. Saba,I. Hashmi,M. A. Awan, et al. (2012) Distribution, toxicity level, and concentration of polycyclic aromatic hydrocarbons (PAHs) in surface soil and groundwater of Rawalpindi, Pakistan. Desalination and Water Treatment 49: 240-247. 10.1080/19443994.2012.719329

24. Shimada,M. Nohchi,X. Yang, et al. (2020) Degradation of PAHs during long range transport based on simultaneous measurements at Tuoji Island, China, and at Fukue Island and Cape Hedo, Japan. Environ Pollut 260: 113906. 10.1016/j.envpol.2019.113906

25. Sun,S. Zhang,J. Lan, et al. (2019) Vertical migration from surface soils to groundwater and source appointment of polycyclic aromatic hydrocarbons in epikarst spring systems, southwest China. Chemosphere 230: 616-627. 10.1016/j.chemosphere.2019.05.007

26. Tong,L. Qin,C. Xie, et al. (2017) Distribution of antibiotics in alluvial sediment near animal breeding areas at the Jianghan Plain, Central China. Chemosphere 186: 100-107.

10.1016/j.chemosphere.2017.07.141

27. G. Waigi,F. Kang,C. Goikavi, et al. (2015) Phenanthrene biodegradation by sphingomonads and its application in the contaminated soils and sediments: A review. International Biodeterioration \& 
Biodegradation 104: 333-349. 10.1016/j.ibiod.2015.06.008

28. Wang,Y. Teng,Y. Zhai, et al. (2020) Influence of surface-water irrigation on the distribution of organophosphorus pesticides in soil-water systems, Jianghan Plain, central China. J Environ Manage 281: 111874. 10.1016/j.jenvman.2020.111874

29. Wang,X. Zhang,W. Ling, et al. (2017) Contamination and health risk assessment of PAHs in soils and crops in industrial areas of the Yangtze River Delta region, China. Chemosphere 168: 976-987. 10.1016/j.chemosphere.2016.10.113

30. Wang,T. He,S. Gen, et al. (2020) Soil properties and agricultural practices shape microbial communities in flooded and rainfed croplands. Applied Soil Ecology 147.

10.1016/j.apsoil.2019.103449

31. Wang,X. Ma,G. Na, et al. (2009) Correlations between physicochemical properties of PAHs and their distribution in soil, moss and reindeer dung at Ny-Alesund of the Arctic. Environ Pollut 157: 31323136. 10.1016/j.envpol.2009.05.014

32. Yang,N. Xue,L. Zhou, et al. (2012) Risk assessment and sources of polycyclic aromatic hydrocarbons in agricultural soils of Huanghuai plain, China. Ecotoxicology and Environmental Safety 84: 304-310. https://doi.org/10.1016/j.ecoenv.2012.07.027

33. Yang,S. Qi,Y. Zhang, et al. (2013) Levels, sources and potential risks of polycyclic aromatic hydrocarbons (PAHs) in multimedia environment along the Jinjiang River mainstream to Quanzhou Bay, China. Mar Pollut Bull 76: 298-306. 10.1016/j.marpolbul.2013.08.016

34. T. Yang,Y. Hashimoto,W. J. Wu, et al. (2020) Effects of long-term paddy rice cultivation on soil arsenic speciation. J Environ Manage 254: 109768. 10.1016/j.jenvman.2019.109768

35. Yu,G. H. Huang,C. J. An\& J. Wei (2011) Combined effects of DOM extracted from site soil/compost and biosurfactant on the sorption and desorption of PAHs in a soil-water system. $J$ Hazard Mater 190: 883-890. 10.1016/j.jhazmat.2011.04.026

36. Zhou,R. Yang\& C. Jing (2018) Polycyclic aromatic hydrocarbons in soils and lichen from the western Tibetan Plateau: Concentration profiles, distribution and its influencing factors. Ecotoxicology and Environmental Safety 152: 151-158. https://doi.org/10.1016/j.ecoenv.2018.01.009

\section{Figures}




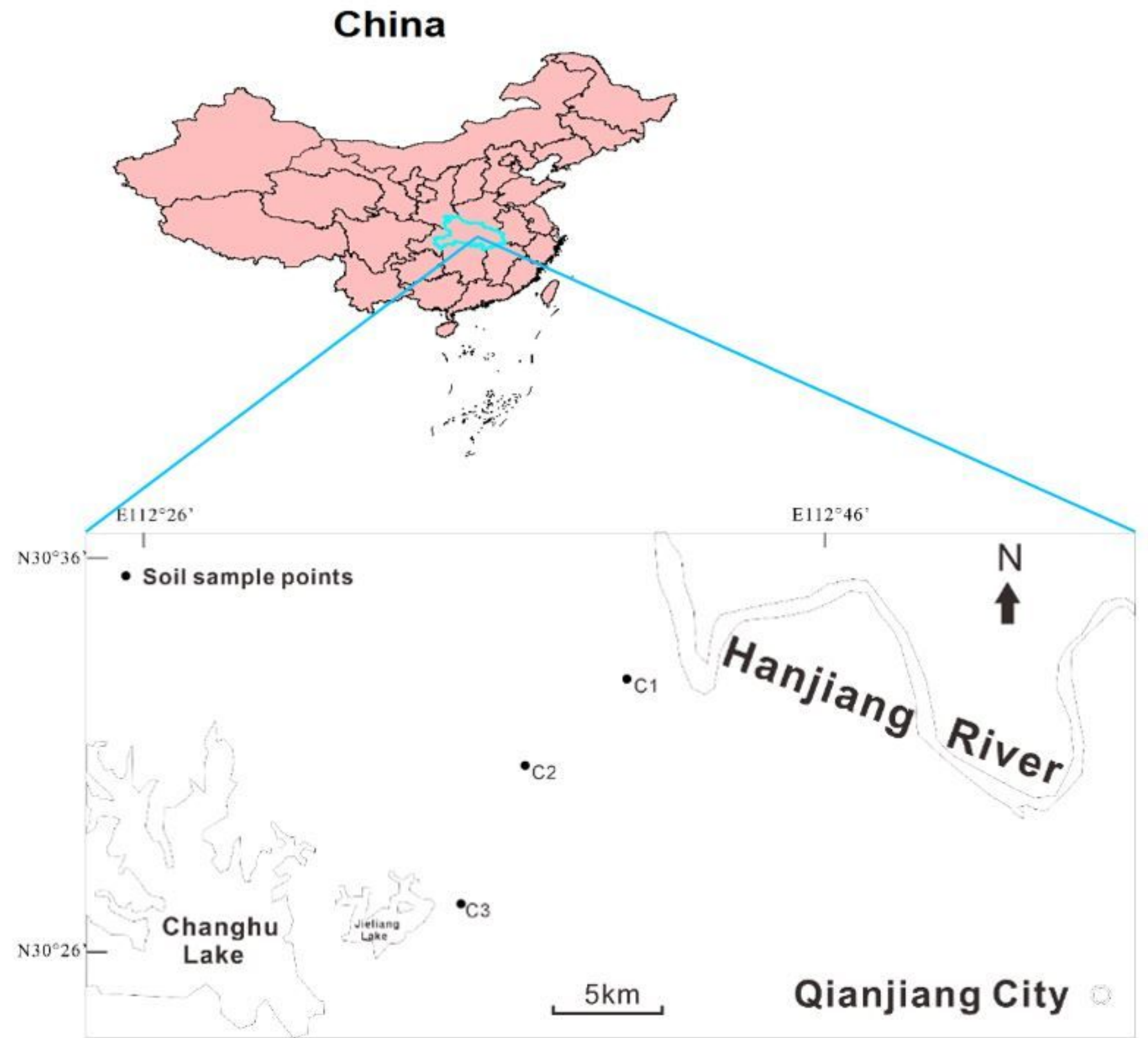

\section{Figure 1}

Location of the study area and sample points in Qianjiang City, Jianghan Plain, Central China. Note: The designations employed and the presentation of the material on this map do not imply the expression of any opinion whatsoever on the part of Research Square concerning the legal status of any country, territory, city or area or of its authorities, or concerning the delimitation of its frontiers or boundaries. This map has been provided by the authors. 

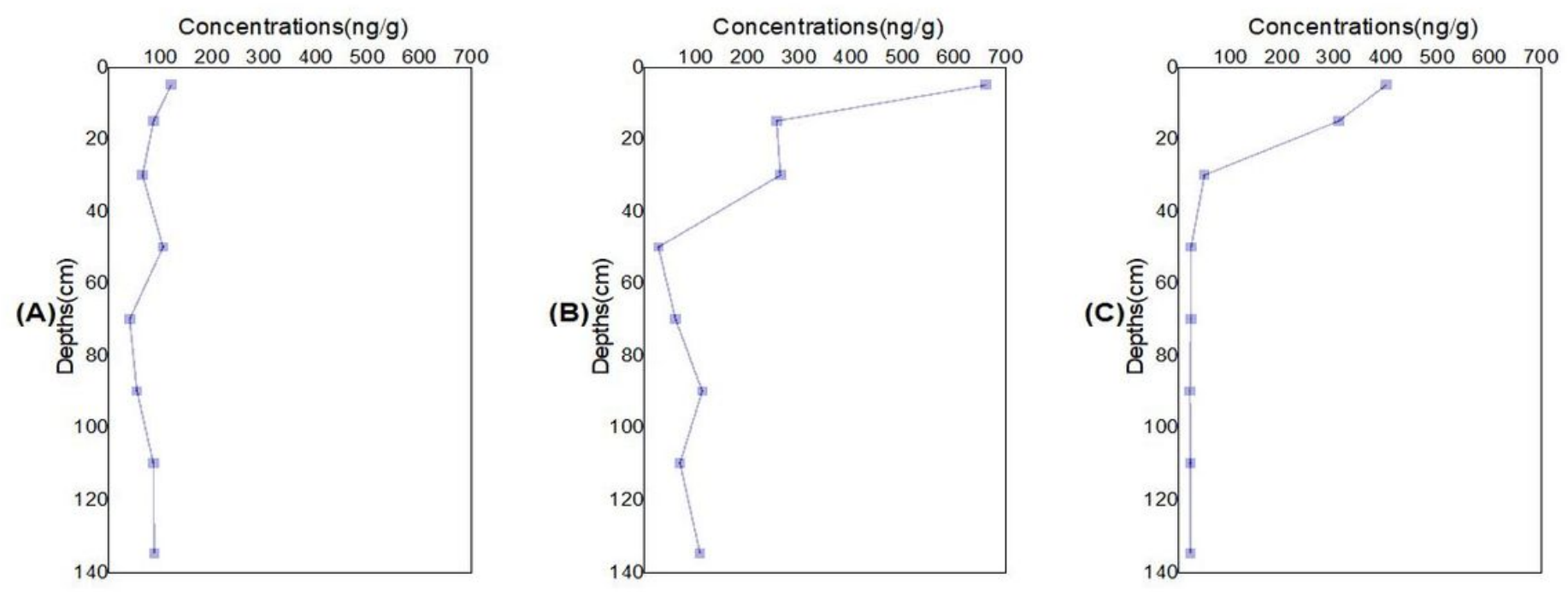

Figure 2

Vertical profiles of total PAHs concentration $(\mathrm{ng} / \mathrm{g})$ in different soil profiles. The (A), (B)and (C) are PF, CF, $\mathrm{RF}$, respectively.
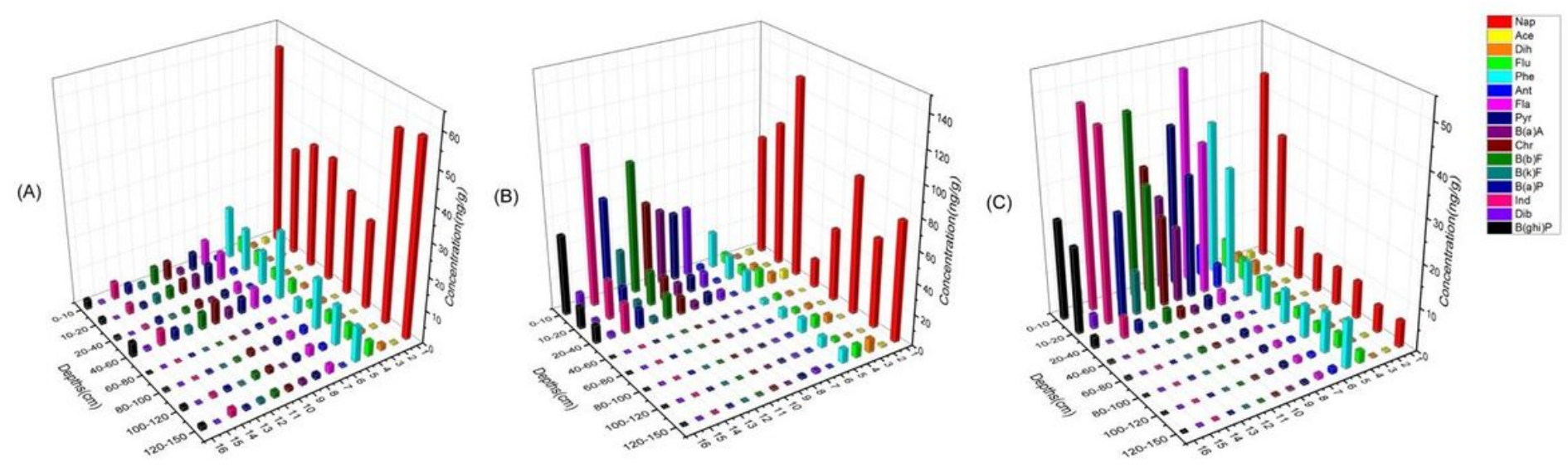

Figure 3

The concentrations of 16 PAHs in soil samples. (A: paddy; B: cotton; C: rape) 


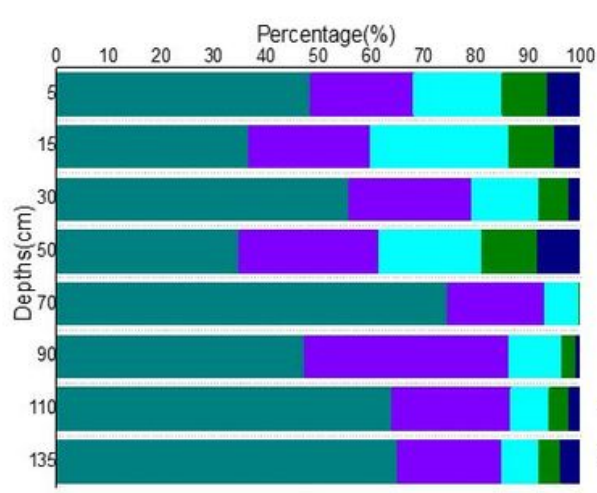

(A)

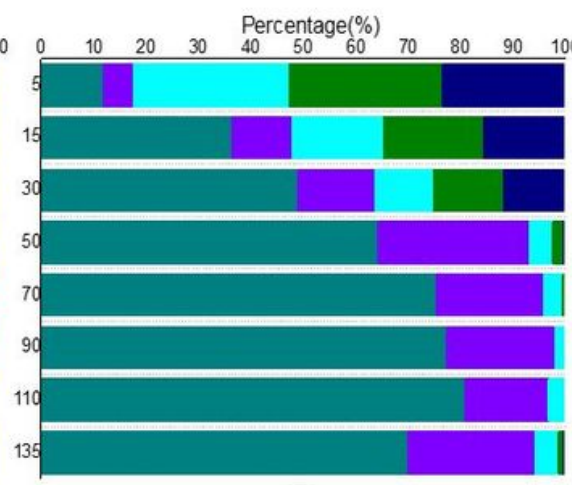

(B)

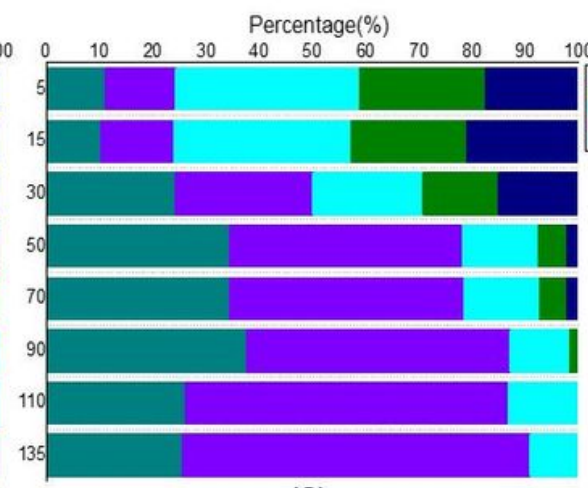

(C)

\section{Figure 4}

The components of PAHs in different soil profiles. The (A), (B) and (C) are PF, CF, RF, respectively. 

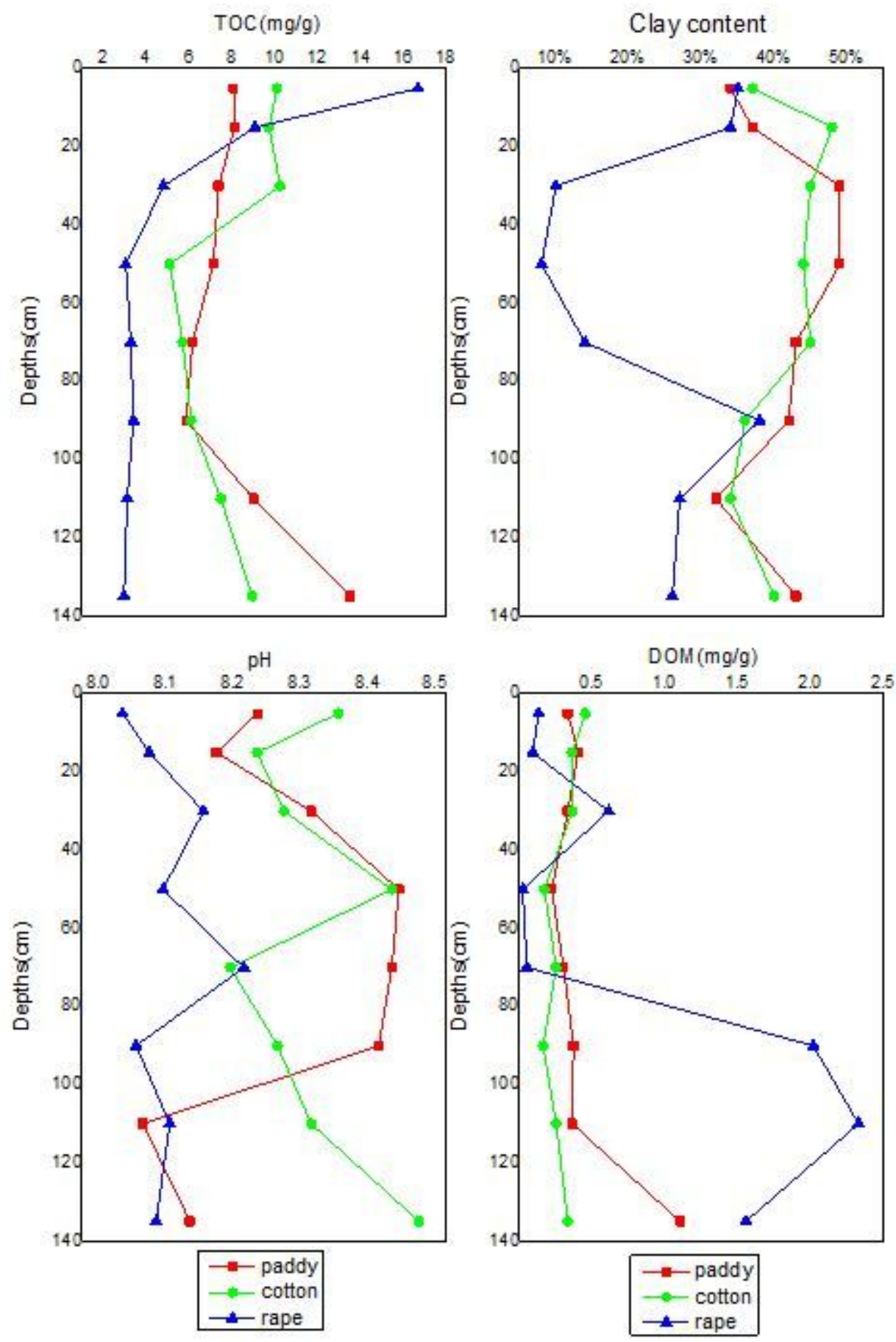

Figure 5

Physical and chemical properties of soil profiles. 


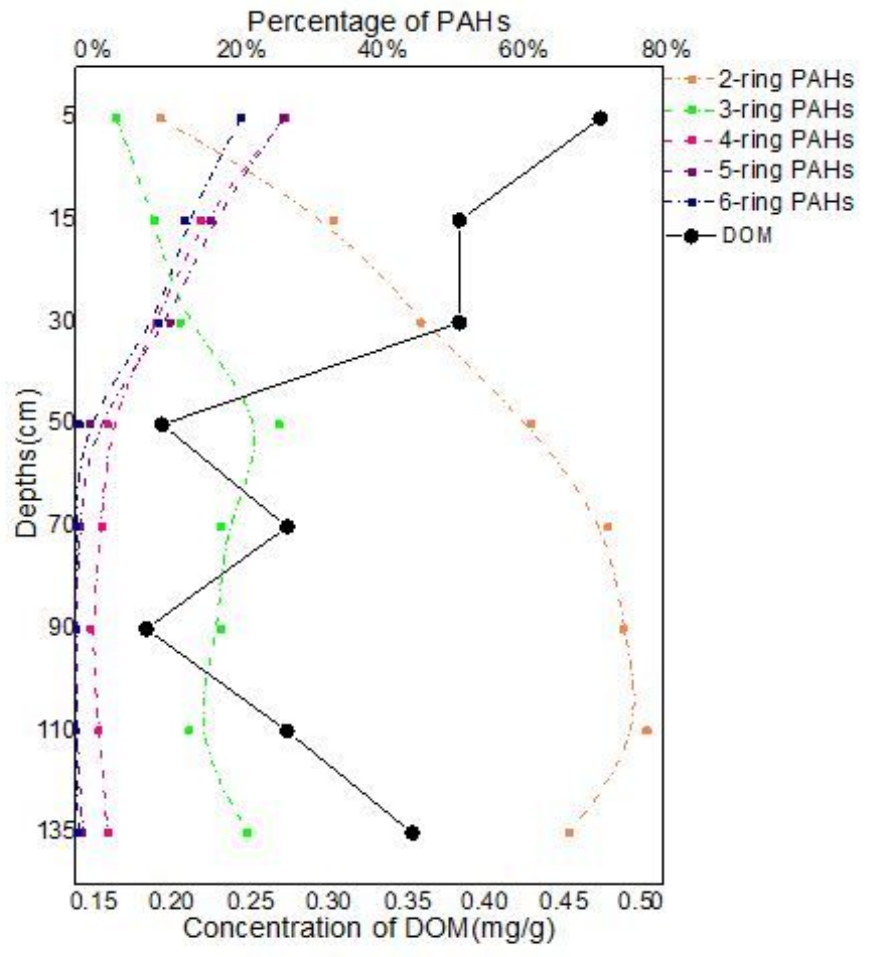

\begin{tabular}{lcc}
\hline & Ring & Coefficient \\
& 2 & -0.819 \\
LMW PAHs & 3 & -0.778 \\
& 4 & 0.843 \\
& & \\
HMW PAHs & 5 & 0.842 \\
& 6 & 0.850 \\
& & \\
& &
\end{tabular}

Figure 6

Correlations between percentage of PAHs and DOM concentrations in CF 


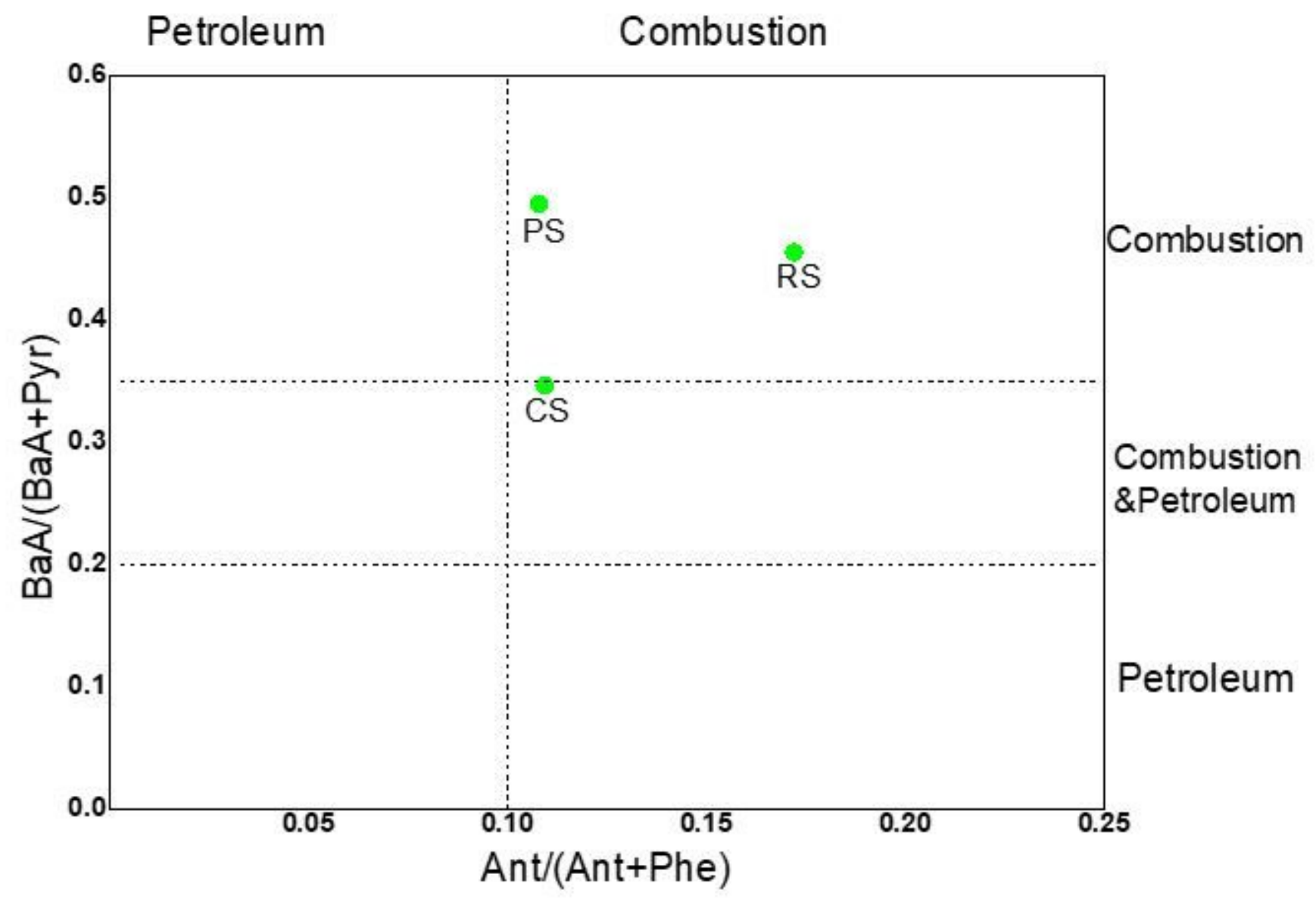

Figure 7

Source identification of PAHs in surface soil 